\title{
Platón presente. La posición de Alain Badiou sobre La República
}

\author{
Plato continues. \\ Alain Badiou's position on The Republic
}

\begin{abstract}
Resumen: Este artículo presenta la reescritura de La República de Platón por parte de Alain Badiou, en su propuesta de traducción de la misma, mediante su propia terminología, al contexto político-cultural actual. Con la interpretación de este filósofo francés, se trata de mostrar la posibilidad de considerar la presencia en el pensamiento del autor griego de ideas propias del Comunismo, entendido como nombre eterno de la emancipación. Por otro lado, se señalan, de la mano de la teoría feminista, los puntos ciegos de la reivindicación de igualdad que realiza Badiou basándose en dicho texto.

Palabras clave: Alain Badiou, Platón, La República, Comunismo, igualdad.
\end{abstract}

\author{
ANDREA C. MOSQUERA VARAS"
}

\section{La pretendida anacronía de la nueva República}

La Filosofía lleva releyendo veinticuatro siglos la obra de Platón, introduciéndose en

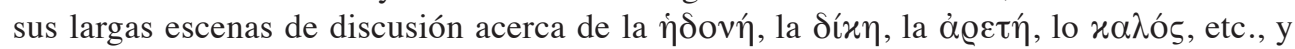
tratando de traducir, en ocasiones a pesar de la interpretación aristotélica, escolástica y neoplatónica cristianizante, esos diálogos que nos son tan lejanos, pero al mismo tiempo tan cercanos. Quizás tratando de hacer olvidar el olvido del acontecimiento socrático-

Fecha de recepción: 19/03/2015. Fecha de aceptación: 21/07/2015.

* Doctoranda en Filosofía en la Universidad Complutense de Madrid, Departamento de Historia de la Filosofía. Ha publicado "Gender consciousness and science versus ideology: Haraway's constructivism plus Althusser's structuralism equals non-essentialist feminism", TC. Maltepe Üniversitesi Fen-Edebiyat Fakültesi Journal 2014/1, ISSN 1303-3115, y "Badiou como acontecimiento", Res Publica. Revista de Historia de las Ideas Políticas, Vol. 18 Núm. 1 (2015), ISSN 1576-4184, pp. 243-257. Sus líneas de investigación son la filosofía de Alain Badiou, el concepto de ley y la teoría feminista. Correo electrónico: acmvaras@ucm.es 
platónico, derivado de las versiones que cada vez se iban alejando más del propósito original, nuestro pensador contemporáneo francés Alain Badiou decidió reescribir la obra más extensa de aquél filósofo, que sería publicada por la Librairie Arthème Fayard en 2012 bajo el nombre La République de Platon: dialogue en un prologue, seize chapitres et un épilogue ${ }^{1}$, traducida al castellano un año después ${ }^{2}$ ¿En qué consiste el resultado de esa relectura que se nos propone? El propio Badiou afirmó ya en 2009 que iba a tratarse de una "hipertraducción"3. Habiendo recorrido este nuevo texto, podemos extraer cierto sentido de lo que ello signifique, pues al compararlo con la República platónica, se observa cómo en su libro hay pasajes enteros parafraseados, otros transcritos a la terminología badiouista, e incluso licencias interpretativas que llegan a invertir las definiciones del escrito original, añadido ello al factor de que, en general, se introduce más la discusión entre los personajes, en lugar de delegar a los interlocutores de Sócrates la única tarea de asentir a todo cuanto se diga.

En cuanto a su estructura, los diez libros pasan a ser, como se explicita en el subtítulo de la obra de este siglo, dieciséis capítulos, además de un prólogo y un epílogo. Los interlocutores que intervienen en el diálogo son, en principio, los mismos que en el ejemplar de Platón: principalmente Sócrates, Glaucón y Adimanto; Céfalo y Polemarco brevemente, y Trasímaco durante un capítulo como interlocutor y dormido en el resto del diálogo. Sin embargo, hay dos modificaciones clave: Glaucón y Adimanto son hermanos de Platón; pero es que, además, Adimanto se convierte en Amantha o, según la traducción al castellano, en Amaranta. Por otro lado, se introduce un narrador que da entrada a la palabra de cada personaje y que, en ocasiones, describe la escena, el momento del día, la sensación que se respira en la habitación y la intención albergada en el discurso de los correspondientes interlocutores; por tanto, Sócrates ya no es quien narra en primera persona el encuentro.

En lo relativo a su contenido, por una parte, Badiou mantiene una proximidad constante al texto, con más o menos variaciones interpretativas, epocales y filosóficas, respetando las situaciones en las cuales se percibe cierta broma entre los personajes, la introducción de mitos, que apuntan a que el asunto tratado sea tal vez inaprehensible bajo un discurso conceptual, y el análisis paralelo al diálogo que se realiza acerca de éste, mediante el cual nuestro autor va poniendo nombre a aquello que ha devenido un tópico platónico, como es

1 A comienzos del verano de 2013 se propagó el rumor de que esta obra sería a su vez transformada en el guión de La Vie de Platon, película que protagonizaría Brad Pitt como el propio Platón, Meryl Streep como su mujer y Sean Connery como Sócrates, todos ellos dirigidos por un Badiou que, según sus palabras, se propondría "llevar a Platón, emblema de la sabiduría universal, al templo contemporáneo de las imágenes comerciales, la máquina propagandística de la vida americana, la capital de la corrupción capitalista: ¡Hollywood!’. La noticia llegó incluso a oídos de Fabien Tarby, interlocutor de Badiou en La filosofía y el acontecimiento: «Me llegó además el rumor de que le gustaría hacer una película» (La filosofía y el acontecimiento. Seguido de una breve introducción a la filosofía de Alain Badiou, Buenos Aires, Amorrortu, 2013, p. 113), cuya curiosidad queda sin embargo sin resolver en la entrevista. Sin embargo, pueden hallarse afirmaciones del estilo que datan ya del año 2009, según las cuales el dramaturgo tenía entre manos la elaboración de dichas película y obra. Entonces llegó a declarar que Platón y Sócrates serían interpretados por el mismo actor, ya que Sócrates sería una creación retrospectiva de Platón, que se convertiría finalmente en el primero. Y, con todo, tras el invierno de 2015 no hay ni rastro de aquélla en las carteleras, y ni siquiera tenemos por seguro que exista su guión.

2 Badiou, A., La República de Platón: diálogo en un prólogo, dieciséis capítulos y un epílogo, Buenos Aires, Fondo de Cultura Económica, 2013.

3 Cf. Badiou, A., «La Idea del Comunismo», en: Circonstances 5. L'hypothèse comuniste, Paris, Nouvelles Éditions Lignes, 2009. 
la "ironía socrática" o la "teoría metafísica de las Formas", del mismo modo que señala las ocasiones en las que se está precisando el método mediante el cual van a proceder a tratar un tema, por ejemplo, por analogía o isomorfismo entre el individuo y el Estado, o la clara distinción entre los momentos en los que se hace filosofía y en los que se hace sociología. Por otra parte, lleva conscientemente a cabo un alejamiento radical del que, en ocasiones, incluso se nos avisa: «Aprovechando la ocasión que me concede Badiou, me sublevo aquí solemnemente contra la interpretación que hace de mi pensamiento [de Sócrates] el hermano de ustedes dos, Platón». ${ }^{4}$ De ello son muestra también tanto las continuas referencias a políticos (Mao, Lenin, Stalin, Hitler, etc.), pensadores (Kant, Rousseau, Marx, Engels, Freud, Lacan, etc.) y poetas (Rimbaud, Mallarmé, Lorca, etc.) de tiempos muy posteriores a la antigua Grecia, como las transcripciones de ciertos razonamientos en forma de fórmula matemática en boca de Glaucón, y la clara omisión de la belicosidad propia de los pueblos griegos continuamente enfrentados, que es sustituida por la idea de internacionalismo y, en consecuencia, como veremos, por la idea de comunismo. En suma, todo ello es realizado por nuestro autor francés con vistas a hacer actual y legible para la contemporaneidad un diálogo que, probablemente, ya fuera lo suficientemente eterno por sí mismo. Sin embargo, echar la vista atrás a un texto filosófico presentando ciertas nociones de nuestra época como propias de la suya, probablemente no sea un error, al que se ha venido llamando anacronismo, sino una tarea sumamente necesaria para reflexionar sobre lo pensado a lo largo de la historia del pensamiento, esto es, de la filosofía, que, en definitiva, no tiene historia; aún es más: «La filosofía no existe sino en cuanto libera a los conceptos de la presión histórica que pretende otorgarles nada más que un sentido relativo» ${ }^{5}$.

\section{La fidelidad del Sujeto...}

Una de las modificaciones clave de Badiou respecto de su maestro griego se da mediante

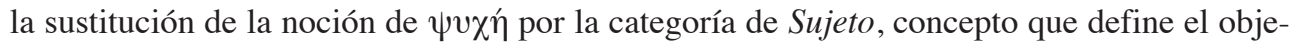
tivo principal de la entera obra de este pensador, que tratará de rescatar aquello que las filosofías englobadas bajo el distintivo de post-modernidad han tratado de derrocar. De acuerdo con Alain Badiou, tanto la filosofía como cada una de sus condiciones (el amor, la ciencia, el arte y la política) tienen el poder de introducir un exceso en la experiencia humana, que transporta al individuo más allá de su finitud anclada en el principio de interés animal, de modo que el Sujeto - que no ha de confundirse con el individuo que a él se incorporaexperimenta cierta inmortalidad, una suerte de eternidad que irrumpe en el tiempo. «El individuo humano, en su singularidad absoluta, como elemento del mundo, pasa a ser parte de ese cuerpo de verdad que aparece». ${ }^{6}$ Los individuos que se incorporan a un procedimiento de verdad constituyen conjuntamente un Sujeto universal, cuya destinación es hacer ver en verdad lo que del ser se expone al pensamiento. El Sujeto es, así, la orientación propia del devenir de una verdad singular. La primacía que - a veces con un lenguaje equívoco, que ha hecho a muchos tildar este pensamiento de dualista - le da Platón al alma sobre el cuerpo,

4 Badiou, A., La República de Platón, op. cit., p. 212.

5 Badiou, A., De un desastre oscuro. Sobre el fin de la verdad de Estado, Buenos Aires, Amorrortu, 2006, p. 17.

6 Badiou, A. y Tarby, F., La filosofía y el acontecimiento, op. cit., p. 86. 
vendría a significar, entonces, que hemos de apoyarnos en el Sujeto que este individuo que somos cada uno la mayoría de las veces puede devenir, esto es, que la regla de actuación ha de ser devenir el Otro que cada uno es, en la medida en que el animal humano es capaz de eso. Entra en juego aquí un concepto que no es propio de ninguna de las condiciones de la filosofía en particular, sino que está a la base de todas ellas: la fidelidad, que nombraría el compromiso de participar en el nuevo Sujeto hecho posible por el acontecimiento y el ánimo de continuar esa tarea abierta para extenderla en el espacio y hacerla durable en el tiempo. Asimismo, la noción de Sujeto está fuertemente vinculada con la de Idea, tal y como leemos en un pasaje de La filosofía y el acontecimiento en el que Badiou se compara con Platón y afirma que «La filosofía es el modo propio según el cual la Idea puede gobernar a la subjetividad». ${ }^{7}$ Una Idea es aquella posibilidad que tenemos presente en el horizonte de nuestro actuar y de nuestro pensar y que, si bien la situación la había considerado imposible, se transforma en posible gracias a un acontecimiento, perpetuándose en el tiempo mediante un procedimiento de verdad, al que se incorpora el Sujeto-de-verdad amoroso, científico, artístico o militante político. Sólo así puede emprenderse una ruptura de la pulsión de repetición del statu quo, de reproducción de la mera animalidad y de su deseo de conservación.

En la dirección de esta sustitución del alma por los Sujetos, no serán ya tres partes, sino tres instancias del Sujeto las que se corresponderán con las funciones de un país, que veremos que serán repartidas de modo igualitario a la comunidad entera. Dichas instancias son el Pensamiento puro, que se encarga de la dirección mental, el Afecto, que es la mediación activa, y el Deseo o energía vital, que es la fuerza motriz de la actividad subjetiva, vinculada a las satisfacciones y las pulsiones. Análogamente, tampoco habrá partes del Estado propiamente dichas, ya que en la propuesta de Badiou no se incorporará la célebre división en "clases" que Platón introduce mediante el mito de los metales (bronce, plata y oro), que tienen distinta proporción según cada alma, de modo que el que predomine en cada individuo determinará su puesto en la sociedad. Se han dado distintas interpretaciones en torno a este pasaje platónico, algunas de las cuales no se conforman con detenerse en una primera lectura que puede llegar a considerar esta división como una estamentización rígida de la sociedad, sino que resaltan el hecho de que la proporción de los metales que se halle en cada alma no depende, ni mucho menos, de la composición de la de sus progenitores; esto es, el destino social de cada uno no será relativo a su nacimiento, sino que el gobernante deberá estar atento a sus capacidades para, fortaleciéndolas por medio de la educación, estimular aquéllas que serán más útiles para la posición que, de acuerdo con las mismas, ocupará en el Estado. Pero Badiou querrá llevar la lectura más allá para romper tajantemente con cualquier atisbo de diferenciación de clases contrarrestando aquél mito a través de un Contradios que hará fundir todos esos metales en la humanidad, de modo que «todos dependerán de una idéntica pertenencia a la igualdad de destino». ${ }^{8}$ No habrá "clases", sino tres funciones principales que habrán de ser garantizadas por todos los ciudadanos que se incorporen a una verdad política: producir, dirigir y proteger. Se introduce así la idea de igualdad $^{9}$ que, en principio, parece contraria a la visión platónica de la sociedad, pues según

7 Ibidem, p. 79.

8 Badiou, A., La República de Platón, op. cit., p. 153.

9 Antes de continuar con el argumento, precisemos el concepto de igualdad, de la mano de Celia Amorós, una filósofa destacada que ha reflexionado profundamente sobre el mismo, recorriendo la entera historia de la 
se lee entre 368d y 376c, ésta nace, según la terminología marxista, de una cierta "división del trabajo". Y, por supuesto, Badiou introducirá un "pero" en esta apuesta: «La división del trabajo esclarece, sin duda alguna, la génesis de las sociedades reales. Pero veremos que no puede servir como principio para la sociedad futura, la que se conformará a nuestra idea de justicia. En ella, todo el mundo tendrá que poder hacer todo o casi todo». ${ }^{10}$ La división del trabajo, según el Platón de Badiou, toma pie en dos convicciones fuertemente arraigadas: por un lado, se dice que cada uno tiene unas dotes naturales distintas a las de los demás y que, según tal disposición, cada uno será apto para realizar una tarea u otra, de lo que se sigue que, por otro lado, cada uno deberá ejercitarse en un solo oficio de manera que consagre la totalidad de su tiempo a ello. En oposición a esto, se introducirá la hipótesis comunista, que se podría considerar como la interpretación de Platón por parte de Badiou por la que éste decidió llevar a efecto la presente traducción. Dos declaraciones suyas son muestra de ello: la afirmación de que «La idea comunista [...] se encuentra ya en Platón» ${ }^{11}$ y el hecho de que en 2009 planease renombrar La República con el título Del(o) común(ismo). ${ }^{2}$ Pero, ¿cómo entender el comunismo?

\section{3. ... a la Idea de Comunismo}

Según explica Fabien Tarby tras su entrevista a Badiou en La filosofía y el acontecimiento, «el comunismo es un nombre admisible para expresar la única verdad política, que es la igualdad de todos sin restricciones». ${ }^{13} \mathrm{El}$ comunismo es la pasión por la igualdad, la resistencia contra la opresión, la suspensión del egoísmo en pos de la Idea de justicia, la lucha por un programa de abolición de la propiedad privada de los medios de producción y, por tanto, del poder privado de explotación. Comunista es «aquel cuya energía política

filosofía desde la perspectiva crítica del feminismo ilustrado: «Una manera expeditiva de obscenizar [dejar fuera de escena] la idea de igualdad consiste en utilizarla como sinónima de "identidad" [...] Por otra parte, con la irrupción en la escena pública de las llamadas "políticas de la identidad" entra en juego un significado del término "identidad" que resulta análogo al de "diferencia" [...] Ahora bien, ¿qué ocurre cuando decimos que las distintas razas o los géneros son iguales? Es obvio que no pretendemos afirmar que los blancos y las gentes de color son idénticos ni que lo sean los varones y las mujeres. [...] La palabra "igualdad", expresiones como "x e y son iguales", se utilizan en estos contextos de tal forma que nada tienen que ver con "identidad" en el sentido de indiscernibilidad [...] Por el contrario, los "iguales" lo son justo porque se puede perfectamente distinguirlos entre sí [...] La igualdad, pues, tal como funciona en los que hemos llamado "contextos de Ilustración", es una idea abstracta y tiene un sentido normativo. Depende de abstracciones en las que se deja fuera todo lo no pertinente a efectos de la relación de "equipolencia" entre $x$ e $y$ y sólo se retiene aquello sobre cuya base se establece, en un sentido no tanto descriptivo como normativo y polémico, la equiparación entre ambos términos. Cuando decimos que los blancos y los negros, los varones y las mujeres son iguales no estamos describiendo una situación de hecho, obviamente, sino un desideratum en el ámbito del deber ser. Para establecer una relación tal se hace abstracción de las diferencias, en principio. Ahora bien: en la medida en la que la idea de igualdad conlleva, como hemos podido ver, su propia radicalización, estas mismas diferencias serán tomadas en cuenta de una forma, en cierto sentido, abstracta, es decir, en tanto que suponen estorbos para que la igualdad postulada como un valor pueda volverse realidad» (Amorós, C., La gran diferencia y sus pequeñas consecuencias... para las luchas de las mujeres, Madrid, Cátedra, 2005, pp.303-309).

10 Badiou, A., La República de Platón, op. cit., p. 98.

11 Badiou, A. y Tarby, F., La filosofía y el acontecimiento, op. cit., p. 30.

12 Cf. Badiou, A., «La Idea del Comunismo», op. cit.

13 Badiou, A. y Tarby F., La filosofía y el acontecimiento, op. cit., p. 196. 
gloriosa está al servicio de la pasión por lo Verdadero».${ }^{14} \mathrm{El}$ nombre inmortal de comunismo no significa necesariamente anticapitalismo, esto es, no requiere del hecho histórico del Capitalismo para poder reivindicarse, sino que es una consigna más universal. La fidelidad a dicha idea se puede mantener y se ha mantenido en distintos procesos políticos a lo largo de la historia, si bien aún no se ha dado propiamente un sostén real para ella: «"comunista" designa la subjetividad transtemporal de la emancipación, todo acontecimiento histórico es comunista». ${ }^{15}$ La Ciudad Ideal platónica en la que un rey filósofo haría reinar a las leyes mismas, se convierte de este modo en una sociedad comunista en la que son cada uno de los ciudadanos comunistas los que detentan el poder en el seno de un "aristocratismo popular": «Que haya uno o varios dirigentes no tiene, en ese caso, ninguna importancia, puesto que todo el mundo puede ser llamado para cumplir todas las funciones». ${ }^{16}$ En cambio, aquello que señale la mayor o menor injusticia de un régimen político será su menor o mayor desviación respecto de dicha Idea comunista. Sorprende, sin embargo, que la historia que trata de dibujarse como la descomposición que se da a través de la transición que parte de la quinta política que es el comunismo, hasta llegar a su máxima corrupción - la tiranía, es decir, el fascismo - , se enuncie, por parte no sólo de Platón, sino también de Badiou, en los términos de un relato psicologista análogo a una relación tradicional padre-hijo que no problematiza las razones que se presentan para justificar la desviación y descomposición del acontecimiento político, que se suponen aritméticas, demográficas y relacionadas con la procreación y la naturaleza de los nacidos. En el seno de dicho relato, sin embargo, nuestro pensador sí introduce algo propio de sus críticas habituales, basándose en la acusación que Platón le dirige a la democracia, que para ambos es caracterizada por una libertad tan sumamente vertiginosa y puramente aparencial y formal, que linda con la nada; se trata de una «"libertad" reducida a la satisfacción obligatoria de los deseos individuales por medio de los objetos disponibles en el mercado». ${ }^{17}$

Volviendo a la idea de que todos pueden cumplir todas las funciones políticas, ello significa, en definitiva, que todos los habitantes de la ciudad están llamados a ser guardianes, es decir, que todos deben, tan rápido como sea posible, llegar a cumplir las exigencias propias de un dirigente que pueda ser llamado guardián, en tanto que defensor de la justicia que moviliza al Sujeto en determinadas circunstancias, sometiendo la energía subjetiva a una Idea. Nuestros guardianes serán nuestros ciudadanos comunistas, que en tanto que llamados a gobernar, deberán ser capaces de hacer avanzar y continuar el proceso político y superar los obstáculos que se presenten reforzando el devenir de dicho proceso. En cuanto a las exigencias que se impone al modo de vida de los guardianes para que puedan llegar a ser excelentes gobernantes, Badiou las resume en un solo precepto: «Hay que abolir la propiedad privada [...] Todo será colectivizado». ${ }^{18}$ Es posible que sea aquí donde pueda encontrarse el germen de comunismo en Platón, dado que él mismo afirma que «nadie poseerá bienes en privado, salvo los de primera necesidad». ${ }^{19} \mathrm{Sin}$ embargo, ello puede llevar a creer que el

14 Badiou, A., La República de Platón, op. cit., p. 374.

15 Badiou, A., De un desastre oscuro, op. cit., p. 16.

16 Badiou, A., La República de Platón, op. cit., p. 196.

17 Ibidem, p. 344.

18 Ibidem, p. 154.

19 Platón, Diálogos IV, República, Gredos, 1986, 416d. 
comunismo propone la abolición de todas las propiedades de cada particular, si bien Marx no clamaba sino por la abolición de la propiedad privada de los medios de producción, esto es, por la prohibición de toda acumulación de capital en manos privadas. Es por ello por lo cual quizás conviene citar, junto con aquéllas, las siguientes palabras: «no fundamos el Estado con la mirada puesta en que una sola clase fuera excepcionalmente feliz, sino en que lo fuera al máximo toda la sociedad» ${ }^{20}$ De forma paralela a esta idea, la política verdadera que es el comunismo es competencia de todos, es nuestro destino colectivo, y sólo allí donde todo se halla en conformidad con una verdadera política hay justicia. Así pues, lo propio del Sujeto y a lo que éste debe referir su acción es la justicia. Pero, ¿qué es la justicia? Es en este punto en el que se produce el mayor alejamiento entre la República y su hipertraducción, pues casi se podría considerar una inversión de su objeto. Para Platón, la justicia ha de consistir en hacer lo que corresponde a cada uno del modo adecuado, y es ello lo que hace al Estado bueno al máximo. Por ello mismo, el mayor mal que le puede advenir al Estado es que las tres clases sociales se dispersen en múltiples tareas y no se ocupe cada una de lo que le es propio. Al contrario, según Badiou, "justicia” quiere decir que «todo individuo debe adquirir la capacidad de ocupar cualquier función en la sociedad, sin que eso implique que se lo desanime a seguir el camino que él imagina es el más apropiado para sus cualidades naturales». ${ }^{21}$ Ello recuerda a la clásica definición de Karl Marx de la justicia, contenida en su Crítica del Programa de Gotha: “¡De cada cual, según sus capacidades; a cada cual, según sus necesidades!". La injusticia consistiría entonces en un doble crimen: «que todos no puedan ser como todos los otros, o que todos no puedan ser diferentes de todos los otros». ${ }^{22}$

\section{La educación de todos frente a la mitología}

Con todo, las capacidades de nuestros ciudadanos y ciudadanas no están dadas y aseguradas de antemano, debido a que «[1]a naturaleza filosófica existe, al principio, en todo el mundo. Pero en casi todos está corrompida». ${ }^{23}$ La convicción comunista, según un Alain Badiou que se muestra en cierto modo rousseauniano, es que el hombre es bueno y que son las patologías de la sociedad, de la familia y del Estado, en resumen: las malas políticas, las que lo corrompen. Por ello, en circunstancias normales, el número de filósofos es escaso, y debemos, por tanto, garantizar las condiciones para que todos puedan serlo. La posibilidad de adecuar la mirada del Sujeto que cada uno es capaz de devenir a la Idea que debe regir el devenir de un país se da por medio de la educación. Como sabemos, según Platón, ésta

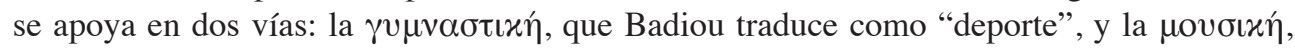
que estaría constituida por las disciplinas científicas, artísticas y literarias para el espíritu. La conjunción de ambas permite que «la incorporación subjetiva a lo Verdadero - aquí la palabra "incorporación" merece ser subrayada - [le confiera] al cuerpo la virtud de la que es capaz». ${ }^{24}$ Los cuerpos, por tanto, en contra de la interpretación dualista que se hace de Platón, no son ajenos al devenir de lo Verdadero. Si no se educa a los ciudadanos tanto en

20 Ibidem, 420a.

21 Badiou, A., La República de Platón, op. cit., p. 175.

22 Ibidem, p. 176.

23 Ibidem, p. 246.

24 Ibidem, p. 133. 
el orden del afecto como en el del espíritu, o bien adormeceremos aquél si sólo se dedican a escuchar música culta y a leer compulsivamente y de forma erudita, y no serán capaces de crítica combatiente alguna; o bien, por medio del culto al cuerpo, abandonarán todo lo que no tenga que ver con éste y se volverán incultos y enemigos del lenguaje racional. Debe haber una tensión y un equilibrio entre estas dos disciplinas para que las dos cualidades propias del Sujeto, que son la valentía y el ansia de saber que es la filosofía, se hallen en armonía y se regulen adecuadamente atendiendo a las circunstancias. Se rompe así con la distinción tajante entre alma y cuerpo, que es sustituida por una educación que acreciente tanto el valor del pensamiento como la fuerza subjetiva. En definitiva, quienes encarnen la función dirigente, que han de ser todos, deberán aunar en un mismo sujeto la capacidad filosófica y la política. Así, el filósofo, que es el antisoñador, el aficionado al espectáculo esencial de las verdades en su singularidad, que se sustrae a los avatares del aparecer, debe a su vez mantenerse firme en los principios comunistas que se encarnan en las instituciones. Según Badiou, si bien la educación da a cada uno los medios para devenir el dialéctico que es capaz de devenir, además «es preciso también que un acontecimiento lo cautive», ${ }^{25}$ y lo sustraiga de la dictadura de la propaganda mediática y sus charlatanes, que adulan lo que existe y reina según la tiranía de la opinión mayoritaria y la alienación general.

Es precisamente en el infinitamente citado pasaje de la Línea de Platón, donde Badiou lee una imagen geométrica que representa el "corte epistemológico 26 " que ha de ejecutarse con respecto a eso en lo que vivimos, en lo que estamos inmersos y que impide la incorporación a un acontecimiento, que se expresa como una ruptura entre aquello que del ser se expone a lo visible y aquello que del ser se expone al pensamiento; dentro del primero, las imágenes son lo más cercano a la oscuridad y a ellas se accede por medio de la suposición; a continuación, la certeza nos hace visibles los objetos del mundo; dentro del segundo, la línea se subdivide en las idealidades analíticas propias del pensamiento analítico, y las idealidades dialécticas, propias del pensamiento puro que, sin imágenes ni apoyos figurados, procede por medio de Ideas hasta un universal anhipotético. En el recorrido de esta Línea, se aprecia una vez más el enlace entre Sujeto y Verdad: «Cuanto más se da un ser en el elemento de la Verdad, más lo piensa el Sujeto en su propia claridad». ${ }^{27}$

En cuanto a la célebre Caverna, con Badiou se convierte en una alegoría cinematográfica en la que encontramos a unos espectadores sentados en sus butacas, mirando una gran pantalla de cine y con unos auriculares en los oídos. No tienen en modo alguno la manera de llegar a la conclusión de que lo que oyen y ven no es sino una sombra de un simulacro que no refiere a verdad alguna; pero el mayor problema es que se acostumbran a yacer en este estado. Se narra entonces la "conversión" - exenta de su significado religioso-, que no es sino la adecuación de la mirada, que se dibuja mediante la anterior Línea, de un miembro del público asistente en su reorientación subjetiva, en su incorporación a una verdad, a lo Verdadero, que traduce la Idea de Bien ${ }^{28}$ platónica. La tarea será, por medio de la educación en todas las funciones propias de un dirigente, hacer posible que todo el mundo salga de la Caverna.

25 Ibidem, p. 247.

26 Noción propia del pensamiento de Gaston Bachelard.

27 Badiou, A., La República de Platón, op. cit., p. 274.

28 Frente a lo escurridizo, huidizo y equívoco de la filosofía de Platón, Badiou promete que dará una noción más precisa de dicha Idea de la que poco se nos dice: «Platón, en La República declara que del Bien sólo puede dar 
Contra aquello que representa lo próximo a la oscuridad en la Línea geométrica y a la pantalla alienante de la Caverna, es decir, contra los mitólogos que nos persuaden de organizarnos en torno a la apariencia y de mentir a coro, creando la ilusión de que somos virtuosos; contra los viejos poetas que hoy se han convertido en el noticiero de cada día, la política verdadera excluye toda representación, toda imitación mecánica y servil. Se entiende entonces por qué «el recelo de Platón contra las artes imitativas es tan sólo un aspecto de su recelo contra la apariencia». ${ }^{29} \mathrm{El}$ arte mimético es imitación de la apariencia, de un simulacro, y está, por ello, muy lejos de la verdad y de la incorporación del Sujeto a ella. Por lo tanto, sólo se aceptará un arte revolucionario nuevo ${ }^{30}$, que es presentación pura y se ajusta a las pautas para educar a los guardianes porque no atiende a lo agradable del discurso, sino a la emulación del buen hombre en sus palabras y acciones. Con todo, en el combate entre la creación de una verdad o el triunfo del conservadurismo, debemos desconfiar de la gloria, de las riquezas y del poder, «pero, por desgracia, también tenemos que desconfiar de la poesía». ${ }^{31}$

Al hilo de esta discusión en torno al lugar de la poesía, encontramos también la cuestión de la existencia de los dioses, ya que son los antiguos poetas los que se han pronunciado acerca de su ser y sus características, constituyéndolos como modelo de acción y, sin embargo, nos los han presentado como seres corruptos y alejados de la virtud. Ello es una razón más para el destierro de los poetas y para introducir un concepto nuevo de divinidad.

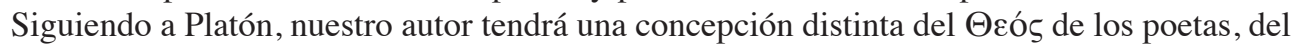
Dios de la tradición judeo-cristiana y del de la Metafísica Occidental. ${ }^{32}$ Badiou rescatará en su filosofía algo de divino e inmortal, pero inmanente al Sujeto. Esta convicción se basa en una aserción que podemos encontrar en Platón, aunque su versión aristotélica ${ }^{33}$ haya sido mucho más citada: «en cuanto el filósofo convive con lo que es divino y ordenado se vuelve él mismo ordenado y divino, en la medida en que esto es posible al hombre». ${ }^{34}$ Es lo que Badiou entiende por la capacidad y posibilidad de todo individuo de devenir el Sujeto que es capaz de devenir, en tanto en cuanto está habitado por una llama, una chispa divina ${ }^{35}$, que constituye la parte de eternidad que nuestra acción envuelve y que reprime el salvajismo

una imagen, nada más. La inmanencia de las verdades [tercer tomo, aún no publicado, de El ser y el acontemcimiento] será en parte una tentativa de [...] volverlo lo menos inefable posible y, por lo tanto, lo más transmisible que se pueda» (Badiou, A y Fabien, T., La filosofía y el acontecimiento, op. cit., p. 159).

29 Ibidem, p. 94.

30 Puede considerarse que los requisitos de este tipo de arte están explicitados en el capítulo dedicado a esta condición o procedimiento de verdad en La filosofía y el acontecimiento, según el cual toda obra de arte debe: 1) estar estructurada de manera sólida, coherente y verosímil; 2) incluir un ingrediente de ruptura de lo tradicional, de novedad, de sorpresa, de modo que no sea clasificable dentro de los géneros estereotípicos estipulados; 3 ) ser elevada, debido a la presencia de una Idea que abra la posibilidad de un pensamiento.

31 Badiou, A., La República de Platón, op. cit., p. 418.

32 Cf. Badiou, A., Breve tratado de ontología transitoria, Barcelona, Gedisa, 2002, pp. 11-23.

33 «En cuanto hombre, en efecto, no vivirá de esta manera, sino en cuanto hay en él algo divino [...] Pero no hemos de tener, como algunos nos aconsejan, pensamientos humanos puesto que somos hombres, ni mortales puesto que somos mortales, sino en la medida de lo posible inmortalizarnos y hacer todo lo que está en nuestro alcance por vivir de acuerdo con lo más excelente que hay en nosotros» (Aristóteles, Ética a Nicómaco, 1177b).

34 Platón, República, 500c-d.

35 Cf. Platón, Fedro, 249d: «Apartado, así, de humanos menesteres y volcado a lo divino, es tachado por la gente

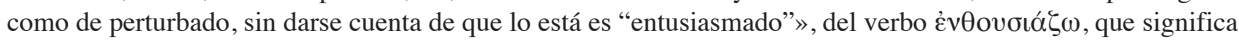
estar en lo divino, estar inspirado o poseído por un dios o una divinidad. 
latente o la dimensión puramente animal. El Sujeto que cada individuo es capaz de devenir es inmortal, eterno, imperecedero, aunque esté compuesto de multiplicidades mortales y a pesar de que su aparición sea contingente, debido al carácter mismo de los acontecimientos, que si bien rompen la lógica propia del mundo, en tanto que elemento de azar, no hay que olvidar que se dan en este mundo y es del vacío de una situación del mundo de la que parten. Los dioses, desde este punto de vista, «son los nombres poéticos de la autoridad inmanente de lo Verdadero». ${ }^{36}$ No hay, por lo tanto, lugar para esperanza poética alguna. No hay, tampoco, "Otro mundo", sino que todo se juega en éste. No hay, por último, redención que nos salve y nos haga irresponsables, sino que en cada una de nuestras acciones se juega la preparación para un acontecimiento, la valentía para incorporarnos a la verdad que se hace posible y la resistencia para continuar la tarea, contra toda traición nacida del egoísmo ${ }^{37}$.

El mito final de $\mathrm{Er}^{38}$ sería la enseñanza que nos precave de la importancia de discernir entre una vida así, orientada hacia la justicia, mediante la que aprendemos lo que es la felicidad, y la que está corrompida por el prestigio social y pre-ocupada por la simple supervivencia, que nos hunde en la desgracia; pues «sólo es verdaderamente feliz aquél que vive bajo el signo de la Idea». ${ }^{39}$

\section{La (des)aparición de Amaranta}

En todo este recorrido hemos dejado al margen - como se ha marginado y olvidado sistemáticamente a lo largo de la historia de la humanidad a las mujeres - a un personaje que Badiou hace entrar en escena desde el comienzo: a Amaranta, joven hermana de Platón y de Glaucón, desenfadada y menos rigurosa que este último, quien se caracteriza por su mente lógico-matemática que tiende a formalizarlo todo. Ella, en cambio, es más crítica y puntillosa con Sócrates, mientras que su hermano parece preocuparse más por mostrar lo que él sabe, en competición con ella. Pues bien, que se introduzca un personaje femenino es, en primera instancia, de agradecer, si bien ello puede ser un arma de doble filo, puesto que todo prejuicio del autor corre el riesgo de quedar reflejado en las zonas en las que el lenguaje riguroso se relaja. Es precisamente de la mano de Amaranta como se introduce un problema clave, presentado y titulado con el capítulo VIII. Mujeres y familias, que problematiza cierta frase sobre la que ya el Adimanto de Platón (entre 449a y 471c) pedía una explicación a Sócrates: «Entre amigos todo se comparte», ${ }^{40}$ lema pitagórico que en La República aludía a las mujeres y a los niños como aquello que es compartido por todos. Badiou se refiere a este problema, sintomáticamente, como «lo que está ligado con el sexo». ${ }^{41}$ Para comprender más a fondo por qué este autor realiza tal equiparación, podemos acudir a lo que en el estudio que lleva a cabo de la política se presenta como una lucha entre Occidente y el Islam que, sin embargo, según Badiou, no se trata sino del combate entre la pornografía o la mercancía y la tradición, que se ejemplifica en el debate sobre el pañuelo islámico. Aun así,

36 Badiou, A., La República de Platón, op. cit., p. 141.

37 Cf. Badiou, A., La ética. Ensayo sobre la conciencia del mal, México, Herder, 2004.

38 Cf. Platón, República, Libro X, 612c-621d.

39 Badiou, A. y Tarby. F., La filosofía y el acontecimiento, op. cit., p. 172.

40 Badiou, A., La República de Platón, op. cit., p. 197.

41 Ibidem., p. 198. 
ello es un pseudo-problema, «producto de una ridícula manipulación de los fenómenos de opinión pública ${ }^{42}$, que oculta detrás a nuestro único enemigo: el Capital. En efecto, según este filósofo comunista, «esconder o mostrar tal o cual parte del cuerpo sólo depende de la contingencia de las costumbres. Es estúpido subirse al techo porque una mujer muestra sus piernas, pero no lo es menos establecer, como lo hacen los franceses, leyes que prohíben que una mujer se cubra el cabello con un velo islámico. Sólo a los cabezas huecas les parece risible o escandaloso lo que no es más que una costumbre diferente de la suya ${ }^{43}$. Quizás - podríamos rebatirle - lo preocupante y aquello que requiere de un análisis no sean las prácticas propias de cada cultura, sino la ideología común de las que son síntoma: el Patriarcado, cuya lógica debemos hacer también objeto de nuestro análisis crítico, si es que nuestro propósito es realizar en el mundo la Idea de igualdad no únicamente para una mitad de la humanidad. Dicho examen procedería del siguiente modo: «ellos cubren de velos a las mujeres cuando transitan por el espacio público. Porque, entre otras razones, las consideran como un objeto sexual del que sólo puede disfrutar el varón que ha acotado para ella su propio espacio privado. Ellos nos interpelan por inmorales y nosotros a ellos por fundamentalistas y fanáticos. Pero, si bien se mira, no son tan distintas las razones por las que unos imponen velos a las mujeres [tradición] y otros las hacen competir en tanto que objetos de exhibición estética [mercancía o pornografía]. Ambos comparten la concepción de las mujeres como sexo» ${ }^{44}$, tal y como acepta nuestro autor, por considerar ridículo y superfluo reflexionar sobre este problema.

Introduciéndonos ya en este capítulo acerca de las mujeres - sive el sexo-, observamos que el filósofo francés simpatiza con la conclusión de Platón en cuanto a que las capacidades dirigentes de cada individuo son independientes de su sexo (si bien es cierto que en ocasiones el pensador griego atribuye como rasgo distintivo del sexo femenino la debilidad) y que, por tanto, mujeres y hombres debían recibir la misma educación - progreso que retrocedería y se estancaría durante siglos en el pensamiento dominante- - Sin embargo, se aleja de Platón en la medida en que éste afirma que las mujeres han de ser comunes a todos, decisión que no comporta en absoluto la disolución del sistema patriarcal ${ }^{45}$, y que quizás tampoco suponga necesariamente abolir la institución familiar, si bien Badiou sí considera que ocurriría esto último. Además, de acuerdo con la célebre tesis de Engels ${ }^{46}$, cree que la familia es solidaria con la propiedad privada por ser «el pilar del orden desigualitario [y que por ello] da cuerpo a las ideas propiamente obscenas de patrimonio, de heredad, de herencia, de superioridad por

42 Badiou, A. y Tarby. F., La filosofía y el acontecimiento, op. cit., p. 50.

43 Badiou, A., La República de Platón, op. cit., p. 202.

44 Amorós, C., «Ética y Antropología», en: C. Gómez y J. Mugueza (eds.): La aventura de la moralidad (Paradigmas, fronteras y problemas de la ética), Madrid, Alianza Editorial, 2007, pp. 184-224, nota 5.

45 Siendo lo común lo intercambiable al modo de las mercancías, las mujeres son «aquello que, desde LéviStrauss, sabemos que es el objeto transaccional por excelencia de los pactos - y de los antipactos o conflictosentre los varones» (Amorós, C., Vetas de Ilustración. Reflexiones sobre feminismo e Islam, Madrid, Cátedra, 2009, p. 69).

46 Cf. Engels, F., El origen de la familia, la propiedad privada y el Estado, obra en la que se sostiene que el germen de la desigualdad entre varones y mujeres se encuentra en la originaria división del trabajo, idea que conduce a pensar que la abolición del Capitalismo conllevaría necesariamente el derrocamiento del sistema de opresión patriarcal. 
nacimiento, de sangre, de raza, de desigualdades inevitables...». ${ }^{47} \mathrm{Y}$, sin embargo, queriendo contraponerse en este punto al texto que reescribe, y dando un cobarde paso atrás, Badiou sostiene que debe protegerse una esfera de lo "íntimo" y de la "invisibilidad" - con arreglo a la lógica de la posición tradicional expuesta que confina recelosamente a la mujer- de modo que el concepto patriarcal de familia, como reproductora de desigualdades no sólo económicas, queda intacto de nuevo.

En consecuencia, a pesar de la reescritura en clave comunista que pretende rescatar una interpretación igualitaria de la filosofía platónica, en Alain Badiou se halla también ausente, como en el filósofo griego ${ }^{48}$, la idea que pueda hacer posible la emancipación efectiva de una mitad de la población mundial que se relega al olvido; pero es que ciertamente esa idea ya ha sido pensada por toda una tradición teórica feminista, si bien falta el valor de muchos para que pueda acontecer en el mundo.

47 Badiou, A., La República de Platón, op. cit., p. 209.

48 Para un análisis más pormenorizado del lugar que Platón concede o niega a las mujeres en su obra, Cf. González, A., La conceptualización de lo femenino en Platón, tesis dirigida por Celia Amorós Puente y leída en la Facultad de Filosofía de la Universidad Complutense de Madrid en 1992. 